\title{
Análise sensorial e aceitabilidade de méis de diferentes floradas oriundas de três municípios do Nordeste Paraense
}

Sensory analysis and acceptability of honey from different blossoms from three municipalities in the Northeast of Pará

Análisis sensorial y aceptabilidad de mieles de diferentes floraciones de tres municipios del noreste de Pará

Emanoel dos Santos Vasconcelos ORCID: https://orcid.org/0000-0001-7045-3900 Universidade Federal Rural da Amazônia, Brasil E-mail: emanoeldsvpgm@gmail.com

Silvana da Silva Santos ORCID: https://orcid.org/0000-0003-0283-7552 Universidade Federal Rural da Amazônia, Brasil E-mail: silsilva.agro@gmail.com

Vanessa Mayara Souza Pamplona ORCID: https://orcid.org/0000-0002-2461-2103 Universidade Federal Rural da Amazônia, Brasil E-mail: vanessa.pamplona@ufra.edu.br

Alessandra Epifanio Rodrigues ORCID: https://orcid.org/0000-0002-8375-2923 Universidade Federal Rural da Amazônia, Brasil E-mail:alessandra.epifanio@ufra.edu.br

Graziela Teixeira de Oliveira ORCID: https://orcid.org/0000-0001-6232-0112 Universidade Federal Rural da Amazônia, Brasil E-mail: graziela.to@gmail.com

Michele Velasco Oliveira da Silva ORCID: https://orcid.org/0000-0002-2525-423X Universidade Federal Rural da Amazônia, Brasil

E-mail: michele.velasco.mv@gmail.com

Lilian de Nazaré Santos Diaz ORCID: https://orcid.org/0000-0002-9823-6737 Universidade Federal Rural da Amazônia, Brasil E-mail: lilian.dias@ufra.edu.br

\begin{abstract}
Resumo
O mel é pelo homem como alimento e por suas propriedades terapêuticas desde a pré-história, além de ser uma ótima fonte de diversos nutrientes, nesse sentido é importante conhecer a relação que os consumidores têm com esse alimento. Diante disso, o objetivo deste trabalho foi avaliar o perfil sensorial e a aceitabilidade de méis de três diferentes origens florais. O experimento foi realizado em outubro de 2019, no Laboratório de Tecnologia de Alimentos da Universidade Federal Rural da Amazônia, no campus de Paragominas, Pará. Foram utilizadas três amostras de méis de diferentes origens florais, uma proveniente de Terra Alta, Pará, outra amostra foi proveniente da cidade de Primavera, Pará, e por fim, a última amostra foi oriunda da cidade de Santa Maria, Pará. Os avaliadores leram e assinaram um termo de consentimento livre e esclarecido e posteriormente, preencheram um questionário estruturado. Foi aplicado o teste de aceitabilidade, sendo utilizado a escala hedônica de nove pontos. Foi avaliada a intenção de compra das amostras de mel aplicando-se uma escala estruturada de cinco pontos. Os dados foram organizados em planilhas do Microsoft Excel. Para verificar qual amostra de mel teve maior aceitação pelos avaliadores realizou-se o teste não paramétrico de Kruskal Wallis, com o auxílio do software SPSS. De modo geral, a amostra que obteve a maior aceitação foi a amostra B, seguida da amostra $\mathrm{C}$ e por último a amostra A.
\end{abstract}

Palavras-chave: Appis melíferas; Consumo; Perfil de consumidores; Teste de aceitação.

\section{Abstract}

Honey is by man as a food and for its therapeutic properties since prehistory, besides being a great source of several nutrients, in this sense it is important to know the relationship that consumers have with this food. Therefore, the objective of this work was to evaluate the sensory profile and the acceptability of honey from three different floral 
origins. The experiment was carried out in October 2019, at the Food Technology Laboratory of the Federal Rural University of the Amazon, on the Paragominas campus, Pará. Three samples of honeys of different floral origins were used, one from Terra Alta, Pará, another sample from the city of Primavera, Pará, and finally, the last sample was from the city of Santa Maria, Pará. The evaluators read and signed an informed consent form and subsequently completed a structured questionnaire. The acceptability test was applied, using the nine-point hedonic scale. The intention to purchase honey samples was assessed using a five-point structured scale. The data were organized in Microsoft Excel spreadsheets. To verify which honey sample was most accepted by the evaluators, the Kruskal Wallis non-parametric test was performed, with the aid of the SPSS software. In general, the sample that obtained the greatest acceptance was sample $\mathrm{B}$, followed by sample $\mathrm{C}$ and lastly sample $\mathrm{A}$.

Keywords: Appis melíferas; Consumption; Consumer profile; Acceptance test.

\section{Resumen}

La miel es por el hombre como alimento y por sus propiedades terapéuticas desde la prehistoria, además de ser una gran fuente de varios nutrientes, en este sentido es importante conocer la relación que los consumidores tienen con este alimento. Por tanto, el objetivo de este trabajo fue evaluar el perfil sensorial y la aceptabilidad de la miel de tres orígenes florales diferentes. El experimento se llevó a cabo en octubre de 2019, en el Laboratorio de Tecnología de Alimentos de la Universidad Federal Rural de la Amazonía, en el campus de Paragominas, Pará. Se utilizaron tres muestras de mieles de diferentes orígenes florales, una de Terra Alta, Pará, otra muestra de la ciudad de Primavera, Pará, y finalmente, la última muestra fue de la ciudad de Santa Maria, Pará. Los evaluadores leyeron y firmaron un formulario de consentimiento informado y posteriormente completaron un cuestionario estructurado. Se aplicó la prueba de aceptabilidad, utilizando la escala hedónica de nueve puntos. La intención de comprar muestras de miel se evaluó mediante una escala estructurada de cinco puntos. Los datos se organizaron en hojas de cálculo de Microsoft Excel. Para verificar qué muestra de miel tuvo mayor aceptación por parte de los evaluadores, se realizó la prueba no paramétrica de Kruskal Wallis, con la ayuda del software SPSS. En general, la muestra que obtuvo mayor aceptación fue la muestra B, seguida de la muestra $\mathrm{C}$ y finalmente la muestra $\mathrm{A}$.

Palabras clave: Appis melíferas; Consumo; Perfil de consumidor; Examen de ingresso.

\section{Introdução}

Desde os primórdios, o homem já se alimentava do mel e usava suas propriedades terapêuticas no tratamento de doenças, sua extração ocorria de maneira predatória e devido ao manuseio inadequado e agressivo, era comum haver elevada mortalidade das abelhas. Entretanto, com o tempo, o homem foi aprendendo a conduzir adequadamente seus enxames, instalando-os em colmeias racionais mais próximas a sua residência, tornando a criação de abelhas uma das atividades mais importantes do mundo associada a exploração na fabricação de mel e serviços de polinização (Empresa Brasileira de Pesquisa Agropecuária (EMBRAPA), 2007; Mel, 2017; Serviço de Apoio às Micro e Pequenas Empresas (SEBRAE), 2018).

Em relação as questões nutricionais, o mel além de ser um adoçante natural pois se configura em um alimento rico em carboidratos, apresenta vários nutrientes minerais. Além de atuar no fortalecimento do sistema imunológico, estimula a produção de anticorpos e a atividade das células de defesa, bem como o combate a radicais livres maléficos ao organismo humano. Além de ser bastante explorado no setor de cosméticos, como na fabricação de cremes, máscaras de limpeza facial, tônicos, entre outros, devido as suas qualidades adstringentes e suavizastes (Ribeiro et al., 2009; Saúde, 2017; Teixeira, 2017).

Na região Norte, o Pará é o primeiro Estado da Amazônia a iniciar na produção de mel, chegando a produzir 558.604 quilogramas em 2018. Esses números estão relacionados ao aumento de incentivos na atividade por meio de fomento, capacitação e melhoria da infraestrutura que vem sendo criada no estado. Basicamente, todos os municípios paraenses são produtores, o que ajuda o estado a se manter com cerca de $76 \%$ de toda produção de mel do Norte do Brasil, com destaque para os municípios de Capitão Poço, Viseu e São João de Pirabas que concentram o maior número de apicultores (Agrolink, 2009; Dol, 2017; Instituto Brasileiro de Geografia e Estatística (IBGE), 2019).

A classificação do mel está ligada a quantidade de plantas utilizadas para produzi-lo, que irá influenciar em suas características organolépticas como cor, sabor, aroma, umidade e viscosidade, (Venturi; Sarcinelli, \& Silva, 2007; Ribeiro et al., 2009), por exemplo, existe o monofloral que é feito a partir do néctar de uma única flor, e o polifloral elaborado com o néctar de várias espécies florais. 
As características do mel interferem na aceitação desse alimento por parte dos consumidores, por isso é necessário que seja submetido a análise sensorial. Este procedimento transformou-se em ferramenta indispensável para que as indústrias possam alcançar os níveis de excelência dos seus produtos e atender as exigências do mercado consumidor, cada vez mais consciente e atento. A qualidade sensorial dos alimentos e a garantia de sua continuidade proporcionam que se mantenha consumidores fiéis a um determinado produto em um mercado cada vez mais exigente e competitivo, onde a oferta de muitos produtos semelhantes é grande (Teixeira, 2009; Duas Rodas, 2019).

Segundo Sensenova (2017), na realização dos testes, os provadores devem ser orientados sobre as características que devem avaliar e com isso faz-se o uso da escala hedônica, que precisa ser de fácil compreensão para o provador. Essa escala é um método de graduação da preferência em níveis quantitativos para alimentos, há várias escalas, no entanto, a mais comum é a estruturada com nove itens desde o desgostei extremamente ao gostei extremamente com notas de 1 a 9 nessa ordem. Também são atribuídos valores como 2, 3, 4, 5, 6, 7 e 8 com os itens respectivamente: desgostei muito, desgostei moderadamente, desgostei pouco, indiferente, gostei pouco, gostei moderadamente e gostei muito (Sensenova, 2017; Scribd, 2019). Há também o teste de ordenação de preferência onde o indivíduo manifesta o seu parecer em relação ao produto que lhe é oferecido, uma série de amostras é apresentada para que seja ordenada de acordo com a preferência do julgador (Instituto Adolf Lutz, 2008).

Portanto, o objetivo deste trabalho foi avaliar o perfil sensorial e a aceitabilidade de méis de floradas diferentes, bem como verificar os atributos sensórias de maior preferência pelo consumidor e identificar a florada que produziu o mel de maior aceitabilidade.

\section{Metodologia}

O experimento foi realizado em outubro de 2019, no Laboratório de Tecnologia de Alimentos da Universidade Federal Rural da Amazônia (UFRA), no campus de Paragominas, Pará. Foram utilizados três amostras de méis de diferentes origens florais, coletados em municípios diferentes do estado do Pará, sendo uma proveniente de Terra Alta, onde o mel é formado por várias espécies de plantas como Passiflora edulis Sims (maracujá), Malpighia punicifolia L (acerola), Citrus reticulata Blanco (tangerina), Citrus sinensis L. Osbeck (laranja), Euterpe oleracea Mart (Açaí), Spondias lutea L (taperebá), Hylocereus undatus (pitaya) e Averrhoa carambola L (carambola); outra amostra foi proveniente da cidade de Primavera, onde o mel é de manguezal, sendo a Avicennia germinans L (Sereiba) a espécie floral principal responsável pela sua formação, e por fim, a última amostra foi oriunda da cidade de Santa Maria, onde o mel também é formado por várias espécies florais e as que mais contribuem para sua produção são: Acacia penninervis (acácia), Vernonia polyanthes Less (assa peixe) e Borreria verticillata (vassourinha de botão).

Com a finalidade de alcançar os objetivos propostos no estudo, foi utilizada a técnica de amostragem por conveniência, composta por alunos e servidores da UFRA, campus de Paragominas, Pará, o que totalizou uma amostra de 60 pessoas não treinadas, de ambos os sexos, com faixa etária de 18 a 50 anos. Os avaliadores receberam um termo de consentimento livre e esclarecido, com explicações claras sobre os procedimentos deste trabalho bem como a sua metodologia, posteriormente um questionário estruturado foi aplicado, com o intuito de coletar informações do perfil dos avaliadores. As amostras foram servidas à temperatura ambiente, em copos plásticos, em quantidades aproximada de $10 \mathrm{~g}$, codificadas com as letras A (Primavera), B (Santa Maria) e C (Terra Alta), sendo uma letra para cada amostra com uma ordem de apresentação aleatória. Foram fornecidos água mineral e biscoito de "água e sal" para limpeza do palato entre a prova das amostras.

Foi aplicado o teste de aceitabilidade, para que os avaliadores expressassem o quanto gostaram ou não gostaram de cada amostra, sendo utilizada a escala hedônica de nove pontos. Nesta escala foram atribuídas notas aos atributos julgados 
como cor, sabor, aroma e impressão global, as notas vão desde 1 (desgostei muitíssimo) ao 9 (gostei muitíssimo). Os avaliadores foram dispostos em sala a uma certa distância, os mesmos foram instruídos a não se comunicarem entre si para não haver interferência no preenchimento dos questionários, e posteriormente, fizeram as degustações e preencheram o teste de aceitabilidade.

Após o teste de aceitabilidade foi avaliada a intenção de compra das amostras de mel aplicando-se uma escala estruturada de cinco pontos, perguntando aos avaliadores se certamente comprariam ou não os produtos, caso estivessem disponíveis no mercado, no qual as notas variam desde 1 (certamente compraria) ao 5 (certamente não compraria). As amostras de méis também foram analisadas pelo teste de ordenação-preferência com o objetivo de entender qual mel os avaliadores mais gostaram. Esse teste só pôde ser respondido após os avaliadores experimentarem os três méis, sendo solicitado aos mesmos que ordenassem as amostras em ordem crescente de preferência atribuindo 1 (maior preferência) ao 3 (menor preferência).

Após a aplicação do questionário e do teste de aceitação, intenção de compra e ordenação preferência os dados foram organizados em planilhas eletrônicas, onde foi realizada a análise exploratória de dados com os objetivos de resumir os resultados obtidos em gráficos. Para verificar qual amostra de mel teve maior aceitação pelos participantes da pesquisa, em relação ao sabor, amora, cor, impressão global e intenção de compra, foi realizado o teste não paramétrico de Kruskal-Wallis, com o auxílio do software SPSS (versão 20.0).

\section{Resultados e Discussão}

Dos participantes do estudo 55,00\% são do sexo feminino, no que tange o estado civil 82,46\% são formados por pessoas solteiras, em relação a faixa etária, a maioria $(56,67 \%)$ se situa entre 18 a 23,99 anos. A escolaridade predominante entre os provadores é o ensino superior incompleto $(68,34 \%)$, e a faixa de renda da maioria dos mesmos é de até um salário mínimo $(38,32 \%)$.

Figura 1 - Percentual de entrevistados, de acordo com a frequência de consumo de mel, em Paragominas, 2019.

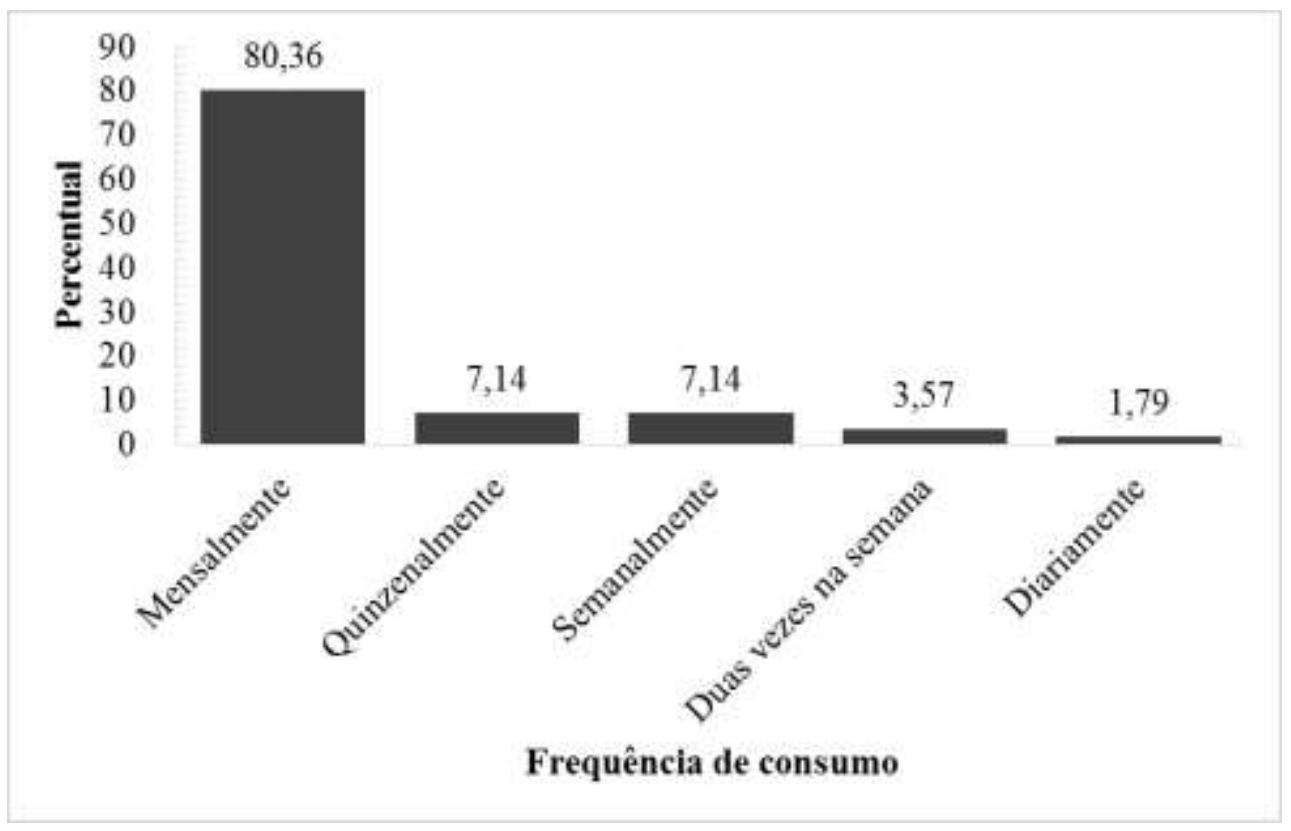

Fonte: Autores.

No que se refere ao consumo de mel, a maioria dos avaliadores afirmaram consumir (60,00\%). Alguns fatores que 
podem influenciar este cenário é que a maioria das pessoas apresenta um baixo consumo, influenciado por uma série de fatores, um deles é que o mel ainda é muito visto como remédio e não como alimento, isso faz com que as pessoas não tenham uma necessidade de consumi-lo com habitualidade, mas sim de forma esporádica quando necessita curar alguma enfermidade (Lima, Souza, Silva, Pontes \& Mota, 2018). Quanto ao hábito de consumo (Figura 1), a maioria, ou seja, 80,36\% consomem mensalmente.

Para um alimento que é tido como de alta qualidade nutricionalmente o mel ainda é pouco consumido, as suas possibilidades de uso ainda não são todas esclarecidas e divulgadas. Desta forma, o que poderia ser feito para aumentar o consumo de mel poderia ser introduzir o hábito na vida das pessoas, por meio de mais divulgação com fomento em relação ao marketing desse produto e esclarecimento quanto aos seus benefícios.

No que diz respeito a diferença entre mel orgânico e tradicional, 70,69\% não sabem a diferença. Já em relação ao tipo de mel consumido, a maioria dos provadores sendo $50,85 \%$, não souberam responder o tipo de mel que eles mais consomem $33,90 \%$ afirmaram consumir de produtor local 10,17\% dizem consumir mel orgânico e 5,08\% de flora silvestre, conforme mostra a Figura 2.

Figura 2 - Percentual de entrevistados de acordo com o tipo de mel consumido, em Paragominas, 2019.

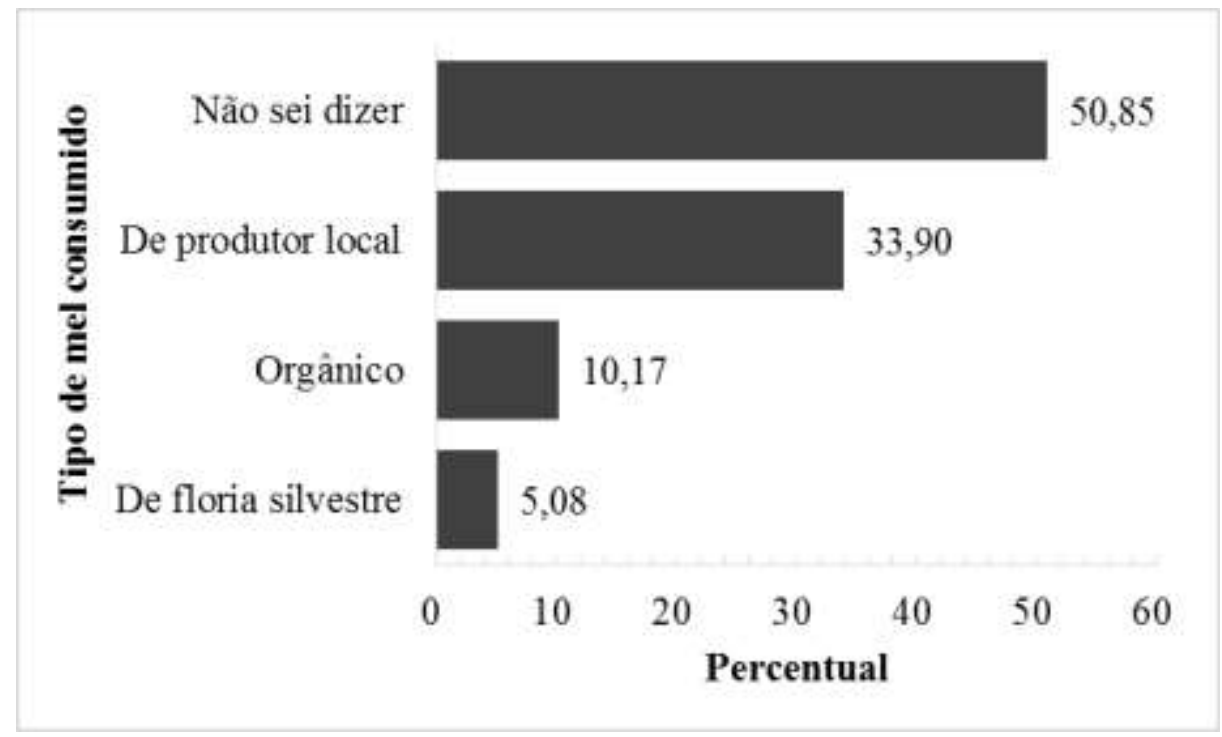

Fonte: Autores.

De acordo com Fonseca (2001), a procura por mel orgânico ocorre por uma classe consumidora cada vez mais exigente, em busca de melhores condições de vida, consumo de produtos isentos de qualquer tipo de contaminação, mas mantendo suas características nutricionais e biológicas, dentro de uma política de qualidade alimentar, em um sistema de produção com menores impactos negativos ao meio ambiente. Este fator associado a deficiência de divulgação do mel orgânico contribui para o desconhecimento deste produto.

Também questionados em relação a preferência no consumo de mel tradicional, a maioria $(55,00 \%)$ consideram indiferente, ou seja, não ligam para o fato de o mel ser tradicional ou não, seguida das pessoas que preferem consumir mel tradicional $(40,00 \%)$, e por fim dos que não preferem $(5,00 \%)$. Esse resultado tem relação com o fato de a maioria dos provadores não saberem a diferença entre mel orgânico e tradicional e por isso opta entre o indiferente e os que preferem mel tradicional. Sobre o costume de ler os rótulos dos méis, a maioria lê às vezes $(79,24 \%)$, em relação ao que eles mais observam nos rótulos dos méis, 41,67\% responderam observar o prazo de validade, seguido da origem $(35,00 \%)$, e em menor porcentagem, o tipo de florada $(5,00 \%)$. Já em relação ao que eles mais observam no rotulo dos méis na hora da compra, a 
maioria dos entrevistados $(41,67 \%)$ respondeu que observa o prazo de validade, seguida da origem $(35,00 \%)$, preço $(31,67 \%)$, e em menor porcentagem, tipo de florada (5,00\%), (Figura 3).

Figura 3 - Percentual de entrevistados, de acordo com as características observadas nos rótulos de méis, em Paragominas, 2019.

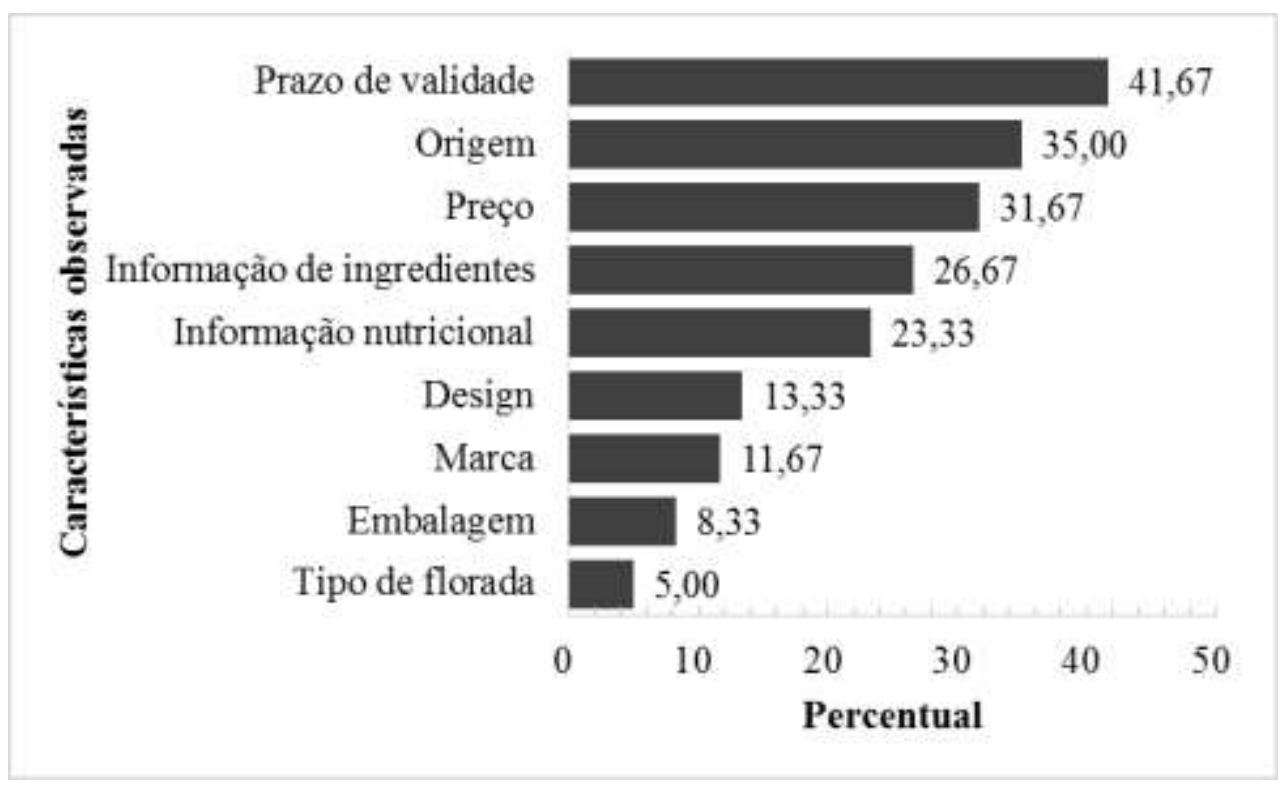

Fonte: Autores.

Ainda não se vê marketing sendo criado sobre o produto para fazer com que estimule o desejo de compra das pessoas, tanto que neste trabalho os participantes relataram que raramente olham para o design e embalagem do mel. Outras questões que pode ter influenciado é que muitas pessoas não compram mel que esteja embalado e com rótulo por acreditarem que este tipo de mel não é feito naturalmente e sim fabricado (Vilckas, Gramacho, Gonçalves, \& Martinelli, 2001).

\section{Teste de aceitação}

\section{a) Sabor}

As amostras B e C apresentaram maior aceitação de sabor pelos entrevistados, ambas tiveram notas medianas iguais a 8, o que corresponde a categoria "Gostei muito" na escala de aceitação (Figura 4). Dos provadores que gostaram da amostra A, os mesmos afirmaram que o sabor deste mel é agradável, além de ter sido considerado mais sutil e pouco ácido. Já os provadores que não gostaram os mesmos afirmaram que a referida amostra parece artificial.

Nascimento (2013), relata que em se tratando de produtos naturais como o mel, a sua legitimidade, ou seja, a certeza de que o produto possa ser natural ou não, é bastante levada em consideração, e complementa que méis adulterados se configuram como um problema mundial.

Para os provadores a amostra B tem um sabor mais suave, o que é considerado para eles mais agradável, os mesmos afirmaram que esse mel não é nem muito forte e nem muito amargo. Dos que não gostaram, consideraram o sabor muito doce. 
Figura 4 - Resultado do teste de aceitação, em relação ao sabor das amostras de mel.

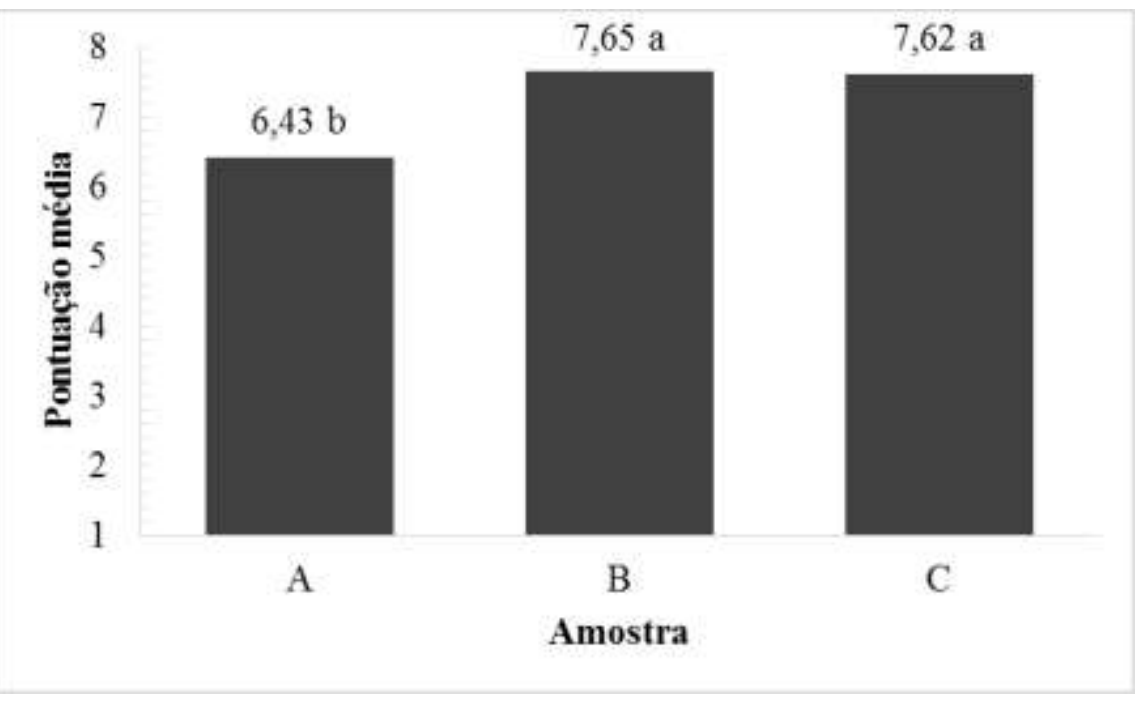

*Médias seguidas por letras iguais na diferem estatisticamente entre si, pelo teste de Kruskal Wallis a 5\% de probabilidade. Fonte: Autores.

A amostra $\mathrm{C}$ foi considerada como tendo um sabor suave, para alguns essa amostra tem um sabor intermediário entre a amostra A e B. Dos que não gostaram consideraram seu sabor enjoativo e que apresenta muita acidez, o que influenciou na ordem de preferência.

Segundo Alvim (2004), o sabor está diretamente ligado à cor do mel, quanto mais escuro, mais rico em minerais se torna, conferindo sabor mais forte, já o mel claro é considerado pobre em minerais e apresenta sabor e aroma mais suave.

\section{b) Aroma}

As amostras B e C apresentaram maior aceitação em relação ao aroma, ambas com médias em torno de 7, o que corresponde a categoria "gostei moderadamente" na escala de aceitação (Figura 5). Nesse quesito as amostras B e C obtiveram a preferência dos provadores, alguns deles consideraram o aroma da amostra $\mathrm{B}$ mais equilibrado e da amostra $\mathrm{C}$ mais perceptível, a amostra A foi considerada com um aroma refinado para os que gostaram. 
Figura 5 - Resultado do teste de aceitação, em relação ao aroma das amostras de mel.

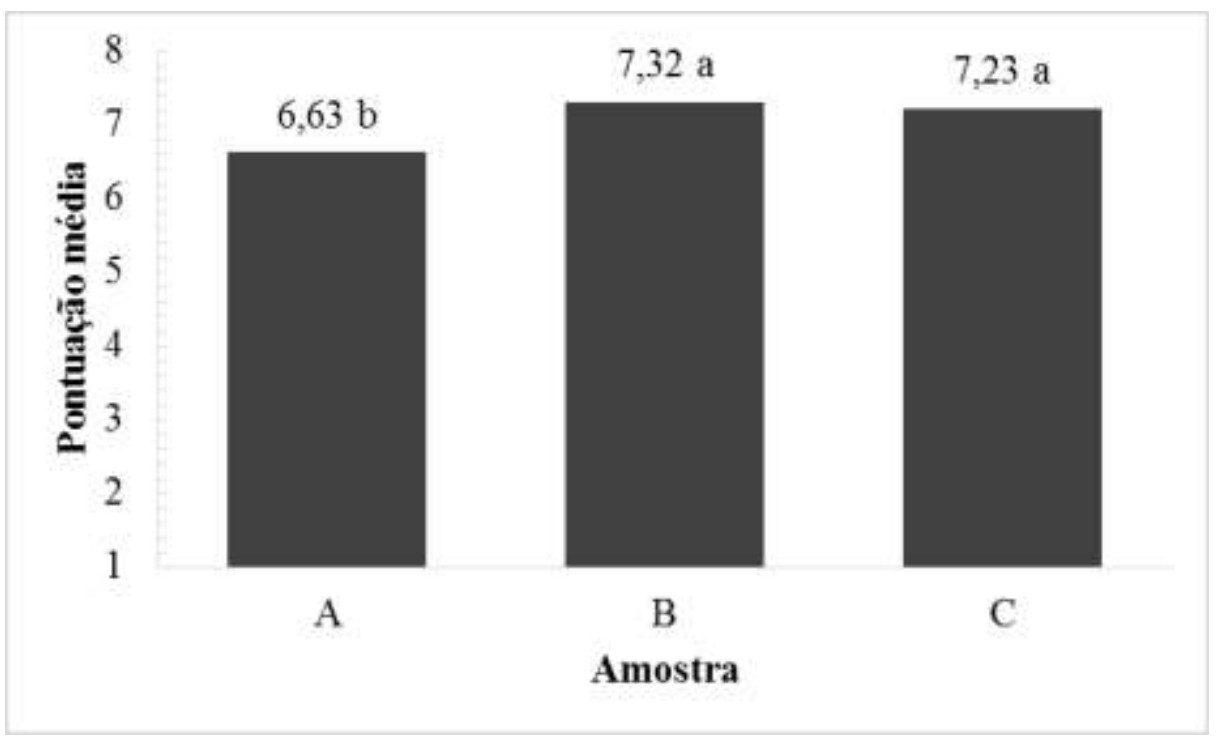

*Médias seguidas por letras iguais na diferem estatisticamente entre si, pelo teste de Kruskal Wallis a 5\% de probabilidade. Fonte: Autores.

\section{c) Cor}

As maiores médias também são atribuídas às amostras $\mathrm{B}$ e $\mathrm{C}$ em relação ao atributo cor, ambas na categoria "gostei muito", na escala de aceitação (Figura 6).

Em relação à cor a amostra B foi tida como a mais atrativa, além de ser considerada mais natural. Para alguns a amostra C possui uma cor mais confiável, em relação a parecer um mel artificial ou não. Já dos que gostaram da amostra A, relataram que a cor do mel foi agradável.

Interessante notar que muitos dos avaliadores disseram que os méis B e C, sendo mais escuros fez com que essas amostras se tornassem mais agradáveis para eles, enquanto que a maioria considerou a amostra A muito clara não se agradando da mesma, no entanto, segundo Alves, Carvalho, Souza, Sodré e Marchini (2005), no mercado mundial o mel é avaliado por sua cor, sendo que méis mais claros apresentam os preços mais elevados, ou seja, são os tipos de méis mais procurados pelos consumidores. 
Figura 6 - Resultado do teste de aceitação, em relação à cor das amostras de mel.

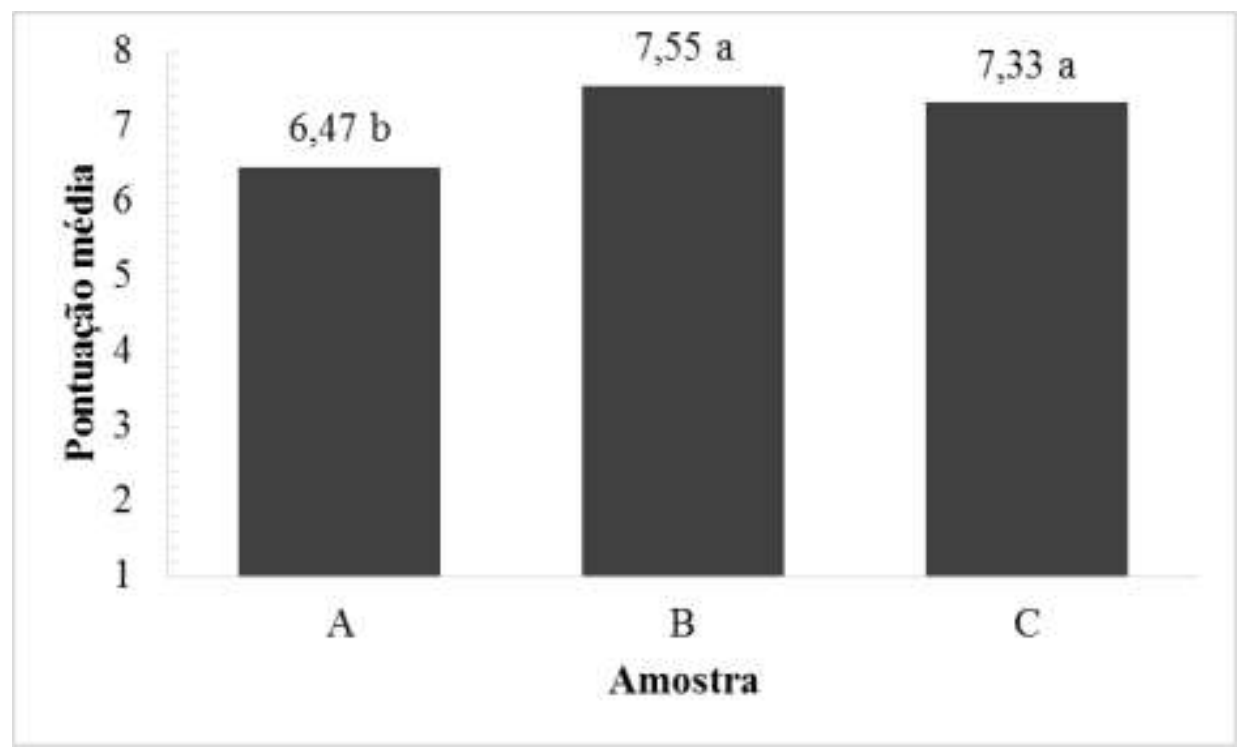

*Médias seguidas por letras iguais na diferem estatisticamente entre si, pelo teste de Kruskal Wallis a 5\% de probabilidade. Fonte: Autores.

Gomes, Souza, Muribeca, Malato, Alves, Gomes, Câmara e Reis (2016), ao traçarem um perfil físico-químico do mel produzido em áreas de manguezal nas localidades de Soure e Salvaterra, localizadas no arquipélago do Marajó, Pará, constataram que, o mel de manguezal apresenta um teor considerável de água por estar inserido em um ambiente em transição entre a terra e água (ambiente de várzea), em suas amostras os mesmos obtiveram variações de cores que vão desde o brancoágua ao branco, o que caracteriza cor mais claras em todos os méis estudados.

\section{d) Impressão global}

Quanto à impressão global, a que mais se destacou e obteve a melhor média foi a amostra $\mathrm{B}$, seguida da amostra $\mathrm{C}$ e por última a amostra A com menor média (Figura 7).

Para Vilckas et al. (2001), um dos critérios mais utilizados na hora da compra do mel são a aparência, cor e a densidade do produto. De uma forma geral os méis $\mathrm{B}$ e $\mathrm{C}$ reuniram atributos que mais chamaram a atenção dos provadores.

As amostras de méis B e C foram consideradas mais consistentes (mais densos), e isso contribuiu para que esses méis aparentassem mais naturais em relação ao mel A, que tinha sua consistência mais aquosa o que conferiu certa insegurança por parte dos provadores.

O mel produzido pelas abelhas no manguezal possui características particulares e diferenciadas do mel produzido em uma floresta onde se encontra uma maior diversidade de espécies florais, pois acaba sendo influenciado pelas propriedades do solo, que envia nutrientes para as plantas agindo na qualidade do néctar que será coletado (Gomes et al., 2016). 
Figura 7 - Resultado do teste de aceitação, em relação à impressão global das amostras de mel.

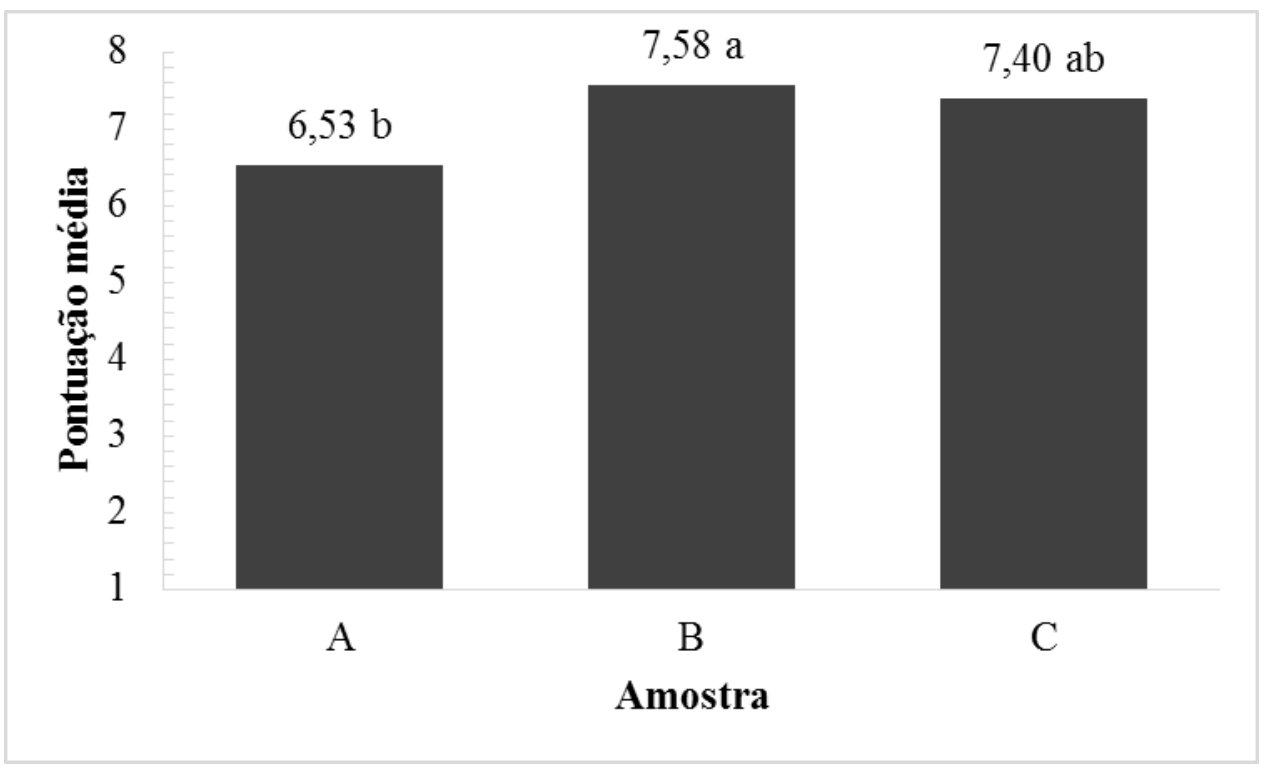

*Médias seguidas por letras iguais na diferem estatisticamente entre si, pelo teste de Kruskal Wallis a $5 \%$ de probabilidade. Fonte: Autores.

\section{e) Intenção de compra}

Sobre a intenção de compra as amostras B e C são as que obtiveram as maiores notas com um média de 4,18 e 4,28 respectivamente, o que corresponde a categoria "possivelmente compraria". Seguindo temos a amostra A com média de 3,62 na categoria "talvez comprasse/talvez não comprasse" (Figura 8).

Figura 8 - Resultado do teste de aceitação, em relação a intenção de compra das amostras de mel.

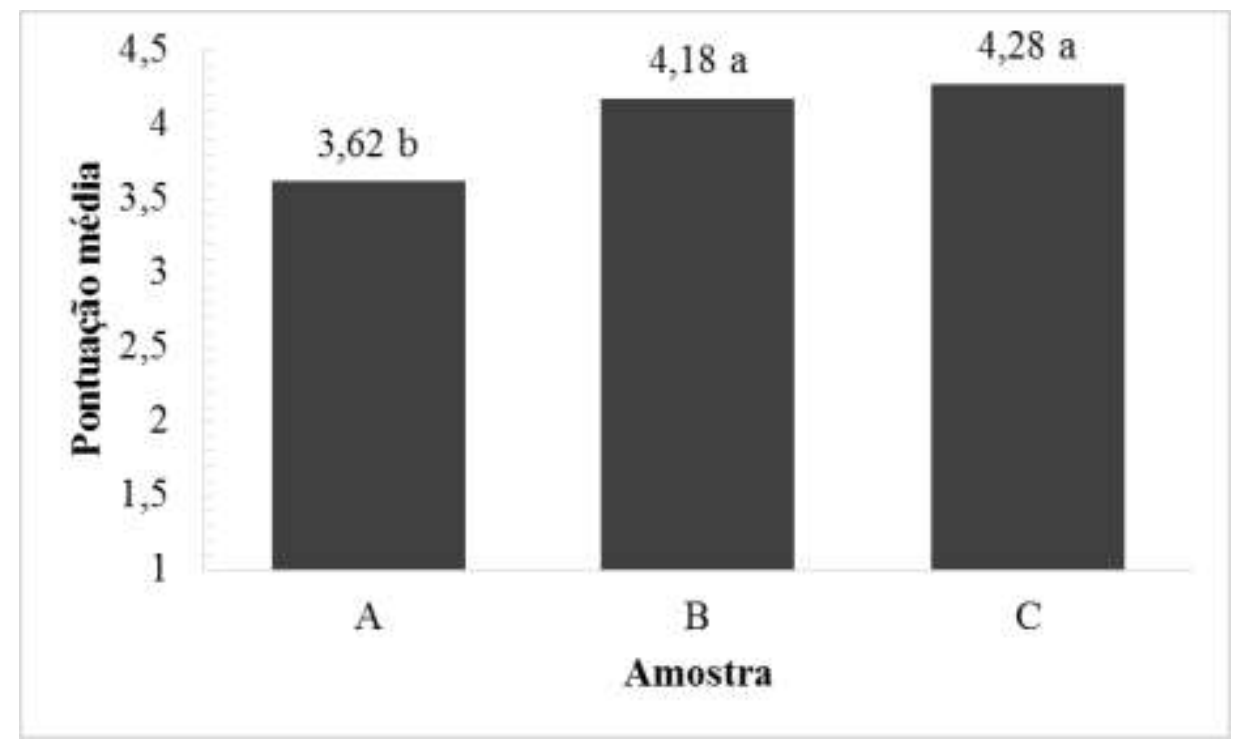

*Médias seguidas por letras iguais na diferem estatisticamente entre si, pelo teste de Kruskal Wallis a $5 \%$ de probabilidade. Fonte: Autores.

Nenhum comentário foi dado especificamente ao teste de intenção de compra, embora, seu resultado tenha sido normalmente influenciado pelo teste de aceitabilidade, no qual as amostras B e C obtiveram as maiores preferencias em todos os atributos. 


\section{Ordem de preferência}

Em relação a ordem de preferência a amostra B obteve a maior porcentagem escolhida como primeira preferência (45,00\%), seguida da amostra C com 36,67\% e por último a amostra A com 18,33\% (Figura 9). Este resultado é apenas um reflexo dos outros resultados precedidos no teste de aceitabilidade e teste de Intenção de Compra.

Como foi citado anteriormente, o fato de os méis $\mathrm{B}$ e $\mathrm{C}$ terem sido formados a partir de várias espécies florais, proporcionou que os mesmos apresentassem em relação as suas características melhores preferencias. Essa diversificação de flora viabilizou maior concentração de minerais o que interferiu diretamente principalmente no sabor e na cor realçando esses atributos.

Figura 9 - Resultado do teste de aceitação, em relação a ordem de preferência das amostras de mel.

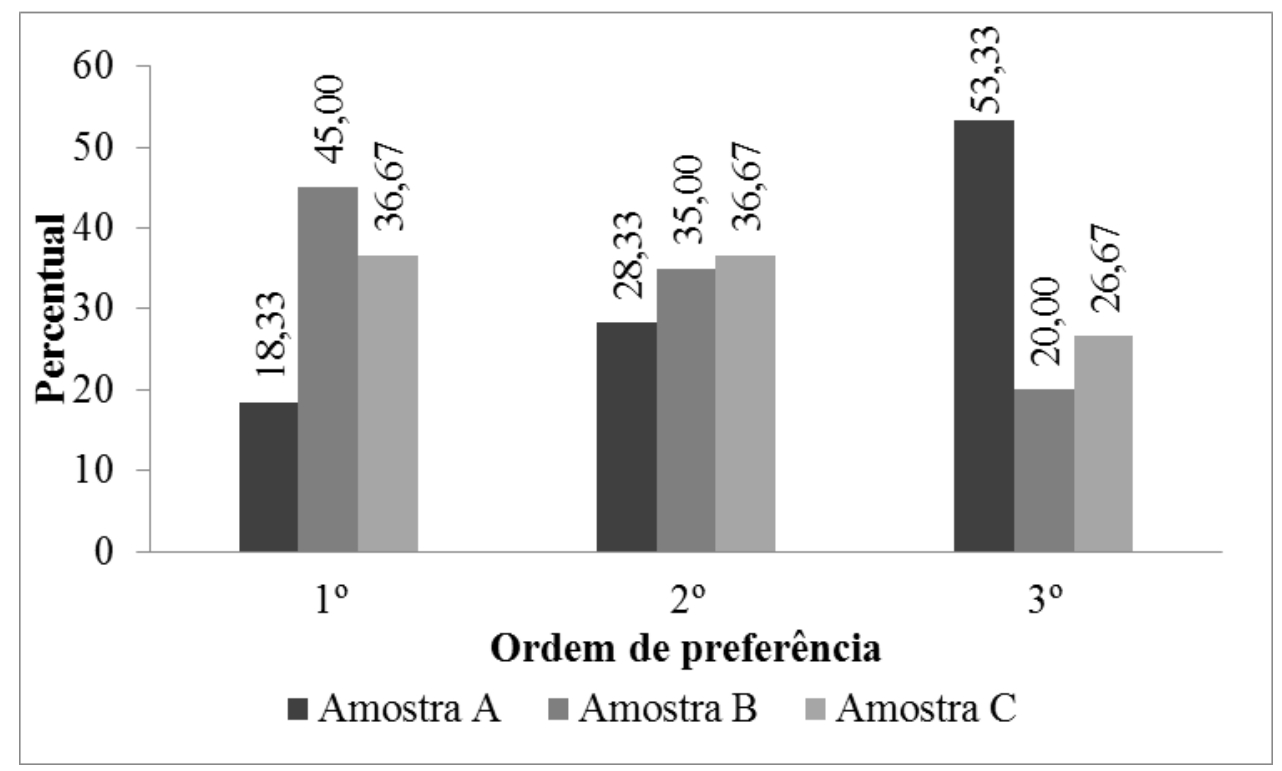

Fonte: Autores.

Ademais a confiabilidade em que o aspecto do produto como um todo apresentou também interferiu, nesse caso o mel A para a maioria dos provadores não foi tão convincente, no geral pareceu se tratar mais de um produto adulterado o que acabou interferindo nas suas características organolépticas, levando os provadores a subtender uma diminuição da sua qualidade e por consequência sendo menos preferível.

\section{Conclusão}

O mel menos aceito em relação as características organolépticas foi o mel de manguezal (amostra A); os méis de floras diversificadas (amostra B e amostra C) obtiveram as maiores taxas de aceitação em relação aos atributos avaliados, com estaque para o mel B.

Contudo, novos estudos envolvendo um público mais amplo, com maior variedade de méis e, preferencialmente, próximo a pontos de comercialização, se faz necessário para entender o perfil de consumidores de mel. Sendo assim, este trabalho foi um ponto inicial, na localidade em que foi desenvolvido, tornando-se referência para outras pesquisas elaboradas com o consumo de mel.

\section{Referências}

Agrolink. (2009). Produção de mel cresce 30\% no Pará. https://www.agrolink.com.br/noticias/producao-de-mel-cresce-30--no-para_99144.html. 
Alves, R. M. O., Carvalho, C. A. L., Souza, B. A., Sodré, G. S. \& Marchini, L. C. (2005). Características físico-químicas de amostras de mel de Melipona mandacaia Smith (Hymenoptera: Apidae). Food Science and Technology, 25(4), 644-50.

Alvim, N. C. (2004). O mel e suas características. Revista cientifica eletrônica de medicina veterinária, (3), 1-7. http://faef.revista.inf.br/imagens_arquivos/arquivos_destaque/ktzYyE7wkOTdgpk_2013-5-20-10-0-38.pdf.

Dol. (2017). Criadores debatem a produção de mel no Pará. diarioonline.com.br/noticias/para/noticia-466507-criadores-debatem-a-producao-de-mel-nopara.html.

Duas Rodas. (2019). E-book traz orientações práticas sobre análise sensorial na produção de alimentos. https://www.duasrodas.com/e-book-trazorientacoespraticas-sobre-analise-sensorial-na-producao-de-alimentos/.

Embrapa. (2007). Criação de abelhas: apicultura. https://www.infoteca.cnptia.embrapa.br/infoteca/bitstream/doc/126300/1/00081610.pdf.

Fonseca, M. F. A. C. (2001). A certificação de alimentos orgânicos no Brasil. http://www.planetaorganico.com.br/trabfem2.htm.

Gomes, P. W. P., Souza, R. F., Muribeca, A. J. B., Malato, B. V., Alves, A. P. C., Gomes, P. W. P., Câmara, D. S. S. \& Reis, J. D. E. (2016). Padrão físicoquímico do mel de apis sp. Produzido em colmeias localizadas em manguezais. http://www.abq.org.br/cbq/2016/trabalhos/10/8930-20566.html.

Guimarães, T. G., Fava, L. W., Santos, M. R., Zanela, M. B. (2009). Perfil do consumidor de mel? uma pesquisa preliminar sobre hábitos de consumo. Salão de Iniciação Científica: Livro de resumos, 21. https://lume.ufrgs.br/handle/10183/41651.

Instituto Brasileiro de Geografia e Estatística. (2019). Produção de origem animal por tipo de produto. https://sidra.ibge.gov.br/tabela/74\#resultado.

Instituto Adolf Lutz. (2008). Métodos físico-químicos para análise de alimentos. (4a ed.), pp. 290-307. Instituto Adolfo Lutz.

Lima, R. F., Souza, A. M. B., Silva, A. O., Pontes, L. R. T. \& Mota, A. V. (2018). Estudo do perfil socioeconômico dos consumidores de mel da região nordeste paraense: uma abordagem a partir do município de terra alta. Ciências Agrárias: Campo Promissor em Pesquisa 5. 06 (1), 44-53. 10.31692/25267701.

Mel. (2019). História da apicultura no mundo. https://www.mel.com.br/historia-da-apicultura-no-mundo/comments.

Nascimento, D. M. D. (2013). Parâmetros de avaliação da qualidade do mel e percepção do risco pelo consumidor (Dissertação de Mestrado). FCUP/ FCNAUP, Porto, Portugal. Recuperado de file:///C:/Users/Positivo/Downloads/Dissertacao_de_Mestrado_Diana_Nascimento.pdf.

Ribeiro, M. I., Matos, A., Almeida, A., Fonseca, A., Fernandes, B., Mota, C., Gonçalves, E., Garcia, E., Pereira, E; Garção, H., Guedes, H., Rodrigues, M. A., Neto, M. \& Abreu, R. (2009). Produtos alimentares tradicionais: hábitos de compra e consumo do mel. Revista de Ciências Agrárias, 32 (2), 97-112. http://hdl.handle.net/10198/2281.

Saúde. (2017). Inclua mel em sua dieta. https://saude.abril.com.br/alimentacao/inclua-mel-em-sua-dieta/.

Scribd. (2019). Relatório Escala Hedônica Análise Sensorial. https://pt.scribd.com/doc/44428219/Relatorio-Escala-Hedonica-Analise-Sensorial.

Sebrae. (2018). Da produção ao mercado consumidor, mel é um excelente negócio. https://sebraers.com.br/apicultura/da-producao-ao-mercado-consumidormel-e-um-excelente-negocio/.

Sensenova. (2017). Conheça a escala hedônica estruturada: a preferência do consumidor de forma direta. www.sensenova.com.br/blog/conheca-escalahedonica-estruturada/.

Teixeira, L. V. (2009). Análise sensorial na indústria de alimentos. Revista do instituto de laticínios Cândido Tostes, 64, 12-21.

Venturi, K. S., Sarchineli, M. F. \& Silva, L. C. (2019). Características do Mel. https://www.google.com/url?sa=t\&source=web\&rct=) \&url=http://agais.com/telomce/b 01107 caracteristicas mel.pdf\&ved=2ahUK Ewj A45j6mu3j AAX9HLKGHQMICT7sQ FA AegQIBRAB\&usg=AOvVawlrEQ6 eLsZJTfgy162Qw8y\&cshid=15650882291 59.

Vilckas, M., Gramacho, K. P., Gonçalves, L. S. \& Martinelli, D. P. (2001). Perfil do Consumidor de Mel e o Mercado de Mel. Mensagem Doce, 64, 05-17. https://www.apacame.org.br/mensagemdoce/64/artigo_.htm. 